\title{
Policy implications for awareness gaps in antimicrobial resistance (AMR) and antimicrobial use among commercial Nepalese poultry producers
}

Anastasia S. Lambrou ${ }^{1 *}$ (D), Gabriel K. Innes², Laura O'Sullivan³, Himal Luitel ${ }^{4}$, Rebanta K. Bhattarai ${ }^{4}$, Hom B. Basnet ${ }^{5}$ and Christopher D. Heaney ${ }^{1,3,6}$

\begin{abstract}
Background: Nepal's poultry industry has increased with a growing middle class, which has translated to an increase in antimicrobial consumption and thus a rise in antimicrobial resistance (AMR). Describing and understanding antimicrobial use practices among commercial poultry producers in Nepal may help minimize the risks of AMR development in both humans and animals and determine the effectiveness of relevant policies.

Methods: From July to August 2018, poultry farmers were randomly recruited from Nepal's Chitwan District to participate in a cross-sectional study. The lead producer in each poultry operation was administered a quantitative structured-survey via a 30-min interview. Participants were asked to provide demographics, production practices, and knowledge about their antimicrobial use practices. Descriptive data analysis was performed to obtain frequencies and compare practices.

Results: In total, 150 commercial poultry producers of whom raised between 300 and 40,000 birds completed the interviews. Only 33\% $(n=49)$ of producers reported knowing what AMR was, and among them only 50\% $(n=25)$ consulted a veterinarian for treatment options. Antimicrobial administration for growth promotion was still employed by $13 \%$ of poultry producers. Similarly, critically important antimicrobial drugs, specifically colistin, were identified at $35 \%$ of participating operations. Producers reported low overall understanding and compliance of withdrawal periods $(n=41 ; 27 \%)$, which may result in both AMR development and adverse health reactions among consumers who ingest antimicrobial residues. Although Nepal has publicized antimicrobial use policies and awareness campaigns to instill healthy production practices, most producers (82\%) were unaware of them.

Conclusion: Many Nepalese poultry producers lack overall antimicrobial use and AMR awareness, which is evidenced by low antimicrobial withdrawal period compliance, use of antimicrobials for growth promotion, and the sustained use of critically important antimicrobials. Improved outreach and educational capacities, paired with increased veterinary resources and extensive monitoring in operations and retail meat products, may increase AMR awareness and policy enforcement.
\end{abstract}

Keywords: Antimicrobial resistance, Withdrawal period, Poultry, Nepal, One health, Health policy

\footnotetext{
* Correspondence: anastasia.lambrou@jhu.edu

${ }^{1}$ Department of International Health, Johns Hopkins Bloomberg School of

Public Health, Baltimore, MD, USA

Full list of author information is available at the end of the article
}

(c) The Author(s). 2021 Open Access This article is licensed under a Creative Commons Attribution 4.0 International License, which permits use, sharing, adaptation, distribution and reproduction in any medium or format, as long as you give appropriate credit to the original author(s) and the source, provide a link to the Creative Commons licence, and indicate if changes were made. The images or other third party material in this article are included in the article's Creative Commons licence, unless indicated otherwise in a credit line to the material. If material is not included in the article's Creative Commons licence and your intended use is not permitted by statutory regulation or exceeds the permitted use, you will need to obtain permission directly from the copyright holder. To view a copy of this licence, visit http://creativecommons.org/licenses/by/4.0/. 


\section{Introduction}

Described as one of the most significant public health crises of our time, antimicrobial resistant organisms contribute to over 700,000 global deaths annually, a number estimated to reach 10 million by 2050 [1, 2]. Antimicrobial resistance (AMR) has been more pronounced in low- and middle-income countries (LMIC) and is projected to rise in the next decades [3]. The growing LMIC health burdens from AMR infections may be due to increased antimicrobial consumption in both human and animal sectors $[4,5]$. It is estimated that animal agriculture purchases up to $73-100 \%$ more antimicrobials than human medicine, which is aligned with a rising middle class that demands animal-based protein [6-8]. The Federal Democratic Republic of Nepal (henceforth Nepal) fits this dual growth and has intensified the animal agriculture sector-notably in the Chitwan district. This district produces $40 \%$ of the nation's egg supply and is dovetailed with increases in antimicrobial drug procurement, which has increased by $50 \%$ between 2008 and 2012 [9, 10]. The veterinary capacity has not caught up with the animal agriculture expansion. Veterinarians have been estimated to only prescribe roughly $30 \%$ of antimicrobials in Nepal, indicating a lack of veterinary oversight on the remaining antimicrobials used, consequent inappropriate usage, and subsequent emergence of antimicrobial resistance [11].

Nepal has responded to injudicious antimicrobial use in the animal agriculture sector through policy adoption that aims to decrease indiscriminate antimicrobial use. For example, the Ministry of Livestock Development's (MoLD) banned the importation of feed enriched with antimicrobials to indirectly reduce growth promotion practices. Nepal has also established a National Action Plan for Antimicrobial Resistance (NAP-AMR), a multi-sectoral committee focused on antimicrobial stewardship for both human and animal sectors [12]. However, veterinarians have little oversight over antimicrobial drugs and little surveillance strategies and data exist to capture the antimicrobial use practices and AMR development trends. It is critical to understand antimicrobial use practices of commercial poultry producers in Nepal to minimize the risks of AMR development in both humans and animals and to evaluate whether current policies and initiatives promote judicious antimicrobial use. This research aimed to evaluate antimicrobial knowledge and antimicrobial use among the Chitwan District's local poultry producers that will provide key elements to evaluate Nepal's current antimicrobial use policies and inform future risk communication and stakeholder training programs.

\section{Methods}

\section{Study design}

A cross-sectional survey of commercial poultry producers was performed in Chitwan District, Nepal between July and August 2018. This study served as one facet of the EcoHealth Net funded One Health Collaboration between the Veterinary School of the Agriculture and Forestry University in Rampur, Chitwan Province, Nepal and the Johns Hopkins Bloomberg School of Public Health in Baltimore, Maryland, United States. The study staff included 12 veterinary undergraduate and postgraduate students from the Agriculture and Forestry University. All study staff were trained in interview administration techniques to ensure the survey questions were asked in a standardized manner and to reduce interviewer and recall biases. Pilot interviews were also conducted at poultry farms not enrolled in the study to further train study staff and monitor and evaluate survey administration.

\section{Commercial poultry producer enrollment}

In 2018, the Nepalese Department of Health Services surveyed Chitwan District poultry operations through a national census structure. The study staff leveraged census information to enroll registered poultry operations through simple random sampling. Study staff interviewed the leadership staff of each operation on-site. The study's sample size was calculated using a two-sided single proportion equation with the assumption that $50 \%$ of farmers in the study have awareness of AMR using the Epitools Epidemiologic Calculator [13]. A sample size of 97 farmers was needed to identify the proportion of $50 \%$ with $95 \%$ confidence and $10 \%$ absolute precision. The sample size goal was exceeded by enrolling 150 farmers and their farms.

\section{Inclusion criteria}

Only consenting operational commercial poultry farms in Chitwan District from July to August 2018 were included in the study population. Within this study, commercial poultry operations were defined as enclosed broiler or layer farms that produced at least 100 chickens, ducks, or turkeys for the commercial market. Poultry operations without a functioning telephone number could not be contacted and were thus excluded. If a consenting facility was no longer operational, a direction was chosen at random on-site to identify and recruit an unenrolled entity. All enrolled operations consented to participation and owners were informed that their participation would not impact their commercial farm registration status. The Institutional Review Board of the Agriculture and Forestry University in Rampur, Chitwan Province, Nepal, approved this study. 


\section{Survey tool}

A quantitative structured-survey was administered to each operation's lead producer through a 30-min interview. The survey tool was developed to answer the primary and secondary research questions using dichotomous and categorial responses on antimicrobial use and AMR knowledge and practices. Participants were also asked open-ended questions to report all antimicrobials they administer during the poultry production process and were requested to present the antimicrobial vessels for clarification and validation. All reported and presented antimicrobial drugs were categorized by class. The survey tool was further refined after a one-week piloting process to increase question clarity and cultural appropriateness.

\section{Statistical analysis and mapping}

AMR knowledge and husbandry practices were analyzed via descriptive statistics. The statistical data analysis was conducted in STATA 14.0 (StataCorp. 2019. Stata Statistical Software: Release 14. College Station, TX: StataCorp LLC). The global positioning system (GPS) point for each operation was recorded prior to the interview. Each GPS point was collected using the Google Maps mobile application. Operations that could not be visited in person were geocoded using Google Maps (Google. Google maps. 2019 ed.: MapData sciences. 2019) and registered physical addresses. The mapping of farms enrolled in the study was produced using ArcGIS (ArcGIS [GIS Software]. Version 10.0 Redlands, CA: Environmental Systems Research Institute, Inc., 2010).

\section{Results}

\section{Commercial poultry producer and farm demographics}

A total of 150 poultry producers from 149 commercial chicken operations and one commercial turkey operation (Tables S1-2) were recruited into the study. Most of the respondents included in the study were male (68\%), of Brahmin Caste (52\%), and completed at least secondary education (65\%). The commercial poultry farms varied in farm size between 300 and 40,000 birds with a mean of approximately 3000 birds. The majority of producers raised layers (66\%) as compared to broilers $(33 \%)$ or both layers and broilers (1\%).

\section{Antimicrobial resistance (AMR) knowledge}

Most (67\%) surveyed commercial poultry producers had little or no knowledge of AMR (Table 1). Farmers with previous AMR knowledge (33\%) reported that they had received AMR education from multiple sources, including veterinarians (51\%) and "occupational experience" (31\%). "Occupational experience" included firsthand experience and secondhand accounts from local producers' experiences with AMR from refractory disease. The majority
Table 1 Commercial poultry farmer antimicrobial resistance (AMR) knowledge in Chitwan District, Nepal, N=150 farmers

\begin{tabular}{ll}
\hline Antimicrobial Resistance Knowledge & Farmer No. (\%) \\
\hline Knowledge of AMR previous to study & \\
Yes & $49(32.7)$ \\
No & $101(67.3)$ \\
Don't know & $0(0.0)$ \\
Sources of AMR knowledge & \\
Veterinarians & $25(51.0)$ \\
Occupational experience & $15(30.6)$ \\
Community members & $8(16.3)$ \\
Newspaper & $8(16.3)$ \\
Social media & $5(10.2)$ \\
Television & $5(10.2)$ \\
Physicians/hospital & $4(8.2)$ \\
Radio & $2(4.1)$ \\
Is AMR a serious threat? & \\
Yes & $44(91.7)$ \\
No & $4(8.3)$
\end{tabular}

Can antibiotic use in poultry impact human health ${ }^{\mathrm{a}}$

Yes 49 (100.0)

No $0(0.0)$

Knowledge of the Nepalese government's antibiotic use policies

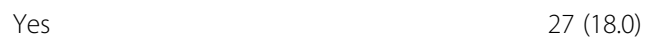

No $123(82.0)$

${ }^{\mathrm{a}}$ Farmers that responded that they had knowledge of AMR previously ${ }^{\mathrm{b}}$ Missing data from one farmer

(92\%) of individuals with previous AMR knowledge acknowledged that AMR resulting from antimicrobial use in poultry is a threat to human health.

Nepal's centralized government has enacted specific policies to restrict the use of antimicrobials in livestock populations as a response to growing AMR concerns. Only $18 \%$ of producers could recall these policies, among whom were well-distributed across the Chitwan District (Fig. 1). Commercial poultry producers were asked a series of questions about antimicrobial use withdrawal periods, which are implemented to reduce human exposure and consumption of antimicrobial residues in animal meat. A majority (57\%) of producers had previous knowledge of withdrawal periods, however, only $48 \%$ of these producers complied with withdrawal timelines.

\section{Antimicrobial use knowledge and practices}

The majority of commercial poultry producers (99\%) self-reported antimicrobial use throughout poultry production (Table 2). Most farmers (69\%) reported use of antimicrobials in the past 3 months, while $22 \%$ reported 


\section{Legend}

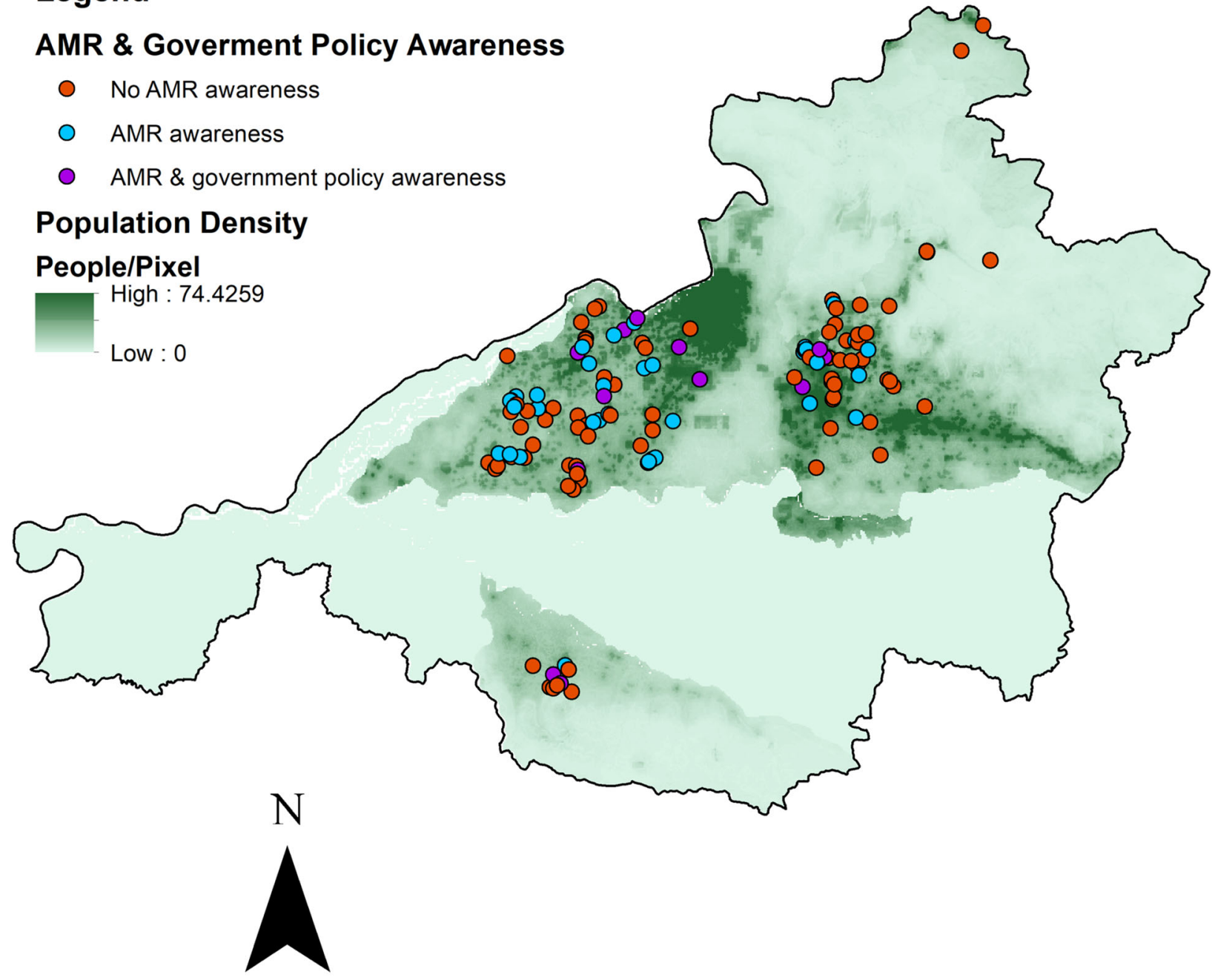

Fig. 1 Map of Chitwan District, Nepal with participating commercial poultry farmers $(N=136)$, their AMR and government policy awareness levels, and the underlying human population density. 14 farms (9\%) mapped outside the study area and were not included in this map, potentially due to mobile service issues in rural border areas of the district.1

use within the past week. Most producers (95\%) cited disease treatment for antimicrobial use. Many also reported using antimicrobials for disease prevention (58\%) and growth promotion (13\%). Only one producer could not recall the reason for antimicrobial use during poultry production. In terms of antimicrobial administration routes, $94 \%$ of farmers dosed antimicrobials through drinking water, $30 \%$ enriched feed with antimicrobials, and $18 \%$ utilized injection routes. Sixty-eight percent of producers obtained antimicrobials for their poultry through veterinarian prescriptions. The remaining producers sometimes (29\%), never (2\%), and did not know
$(<1 \%)$ if they received antimicrobials through veterinary drug prescriptions. Of those who treated their flocks with antimicrobials, most (65\%) producers consulted a veterinarian when they suspected disease in their flocks, $24 \%$ consulted a veterinary technician, and $10 \%$ selftreated.

\section{Farmer antimicrobial knowledge and use in poultry} production

Producers reported antimicrobial knowledge pertaining to brand names, antimicrobial classes, and nonantimicrobial supplements. Of the 149 producers who 
Table 2 Commercial poultry farmer antibiotic use knowledge and practices in Chitwan District Nepal, N=150 farmers

\begin{tabular}{|c|c|}
\hline Antibiotic Use Characteristic & Farmer No. (\%) \\
\hline \multicolumn{2}{|c|}{ Use antibiotics to raise their poultry } \\
\hline Yes & $148(98.6)$ \\
\hline No & $1(0.7)$ \\
\hline Don't know & $1(0.7)$ \\
\hline \multicolumn{2}{|c|}{ Used antibiotics in poultry production in past week } \\
\hline Yes & $34(22.7)$ \\
\hline No & $115(76.6)$ \\
\hline Don't know & $1(0.7)$ \\
\hline \multicolumn{2}{|c|}{ Used antibiotics in poultry production in past 3 months } \\
\hline Yes & $104(69.3)$ \\
\hline No & $44(29.3)$ \\
\hline Don't know & $2(1.4)$ \\
\hline \multicolumn{2}{|l|}{ Purposes of antibiotic use } \\
\hline Disease prevention & $87(58.0)$ \\
\hline Growth promotion & $20(13.3)$ \\
\hline Disease treatment & $143(95.3)$ \\
\hline Don't know & $1(0.7)$ \\
\hline \multicolumn{2}{|c|}{ Administration routes of antibiotics } \\
\hline Feed & $46(30.7)$ \\
\hline Water & $141(94.0)$ \\
\hline Injection & $27(18.0)$ \\
\hline \multicolumn{2}{|c|}{ Use of veterinary prescription for poultry antibiotics } \\
\hline Always & $102(68.0)$ \\
\hline Sometimes & $44(29.3)$ \\
\hline Never & $3(2.0)$ \\
\hline Don't know & $1(0.7)$ \\
\hline \multicolumn{2}{|c|}{ Knowledge of poultry withdrawal antibiotic period } \\
\hline Yes & $85(56.7)$ \\
\hline No & $65(43.3)$ \\
\hline \multicolumn{2}{|c|}{ Knowledge and use withdrawal antibiotic period ${ }^{a}$} \\
\hline Yes & $40(47.6)$ \\
\hline No & $44(52.4)$ \\
\hline \multicolumn{2}{|c|}{ Who do you consult when poultry are sick? } \\
\hline Veterinarian & $97(64.6)$ \\
\hline Veterinary technician & $36(24.0)$ \\
\hline Self-treat & $15(10.0)$ \\
\hline Don't treat & $1(0.7)$ \\
\hline Don't know & $1(0.7)$ \\
\hline
\end{tabular}

${ }^{a}$ Missing data from one farmer

reported antimicrobial use during animal production, 148 could identify at least one antimicrobial. Producers reported using 26 unique drugs, which comprised 13 different classes and drug combinations (Table 3). Almost all producers (93\%) self-reported usage of brands that utilize drug combinations, for example Colidox (Colistin + Doxycycline), Dimoxan (Colistin + Amoxicillin), Neodox (Neomycin + Doxycycline), and Sulphatrim (Sulfamethoxazole + Trimethoprim). Neodox, a combination of neomycin and doxycycline, was the highest reported drug combination used by $71 \%$ of poultry farmers. The antimicrobial drug class most frequently self-reported was polypeptides (35\%), which was driven by the high use of the drug combination colistin (31\%). The second most used antimicrobial family class was fluoroquinolones (30\%), which includes ciprofloxacin, enrofloxacin, and levofloxacin.

\section{Discussion}

Antimicrobial use in Nepal's animal agricultural sector may contribute to downstream AMR infections in humans and other animals through various transmission mechanisms, including direct contact between infected animals and humans, wastewater effluent, and consumption and handling of contaminated animal products. A One Health approach is needed to tackle AMR due to the interconnectedness of the use of antimicrobials in animal agriculture and human health. The Nepal government has enacted policies and antimicrobial campaigns to address the AMR challenge. However, little research has assessed the extent to which Nepal's AMR initiatives have improved overall antimicrobial practices or monitored overall AMR trends in animal agriculture [14]. To the authors' knowledge, this is the first study that has investigated production practices in Chitwan District's commercial poultry industry to gain insight into antimicrobial-use and AMR knowledge.

This study demonstrated AMR knowledge gaps among Chitwan's poultry producers. This lack of AMR knowledge and current policies that address responsible antimicrobial use demonstrates that despite efforts to improve stakeholder outreach from the Veterinary Standards and Drug Administration Office (VSDAO) and the Veterinary Public Health Office (VPHO), widespread policy awareness has yet to reach many producers $[12$, 15]. Effective dissemination is not a new challenge nor isolated to Nepal. Similar observations were reported in Vietnam among poultry producers who tended to score worse on AMR knowledge compared to individuals from other food animal sectors [16]. Gaps also existed regarding the use of critically important human antimicrobials in the poultry industry, such as colistin, fluoroquinolones, and chloramphenicol. The self-reported colistin use is especially concerning as it is a last-line antimicrobial for Gram-negative infections in human patients. Previous widespread use of colistin in animal agriculture propagated resistant bacterial infections in humans and animals, leading to its ban in many countries, including 
Table 3 Antimicrobials used by farmers in commercial poultry production in Chitwan District Nepal, $n=150$ farmers

\begin{tabular}{|c|c|c|c|c|}
\hline Antibiotic Drug Class & $\begin{array}{l}\text { Farmer No. } \\
N=150(\%)\end{array}$ & Self-Reported Antibiotic Drug & ATCvet Code & $\begin{array}{l}\text { Farmer No. } \\
\mathrm{N}=150(\%)\end{array}$ \\
\hline Amphenicol & $1(0.7)$ & Chloramphenicol & QG01AA05 & $1(0.7)$ \\
\hline \multirow[t]{3}{*}{ Aminoglycoside } & \multirow[t]{3}{*}{$35(23.3)$} & Amikacin & QJ01GB06 & $8(5.3)$ \\
\hline & & Gentamicin & QJ01GB03 & $26(17.3)$ \\
\hline & & Neomycin & QJ01GB05 & $1(0.7)$ \\
\hline Beta-lactam & $3(2.0)$ & Amoxicillin & QJ01CA04 & $3(2.0)$ \\
\hline \multirow[t]{2}{*}{ Cephalosporin } & \multirow[t]{2}{*}{$14(9.3)$} & Cefalexin & QJ01DB01 & $11(7.3)$ \\
\hline & & Cefuroxime & QJ01DC02 & $3(2.0)$ \\
\hline \multirow[t]{4}{*}{ Fluoroquinolone } & \multirow[t]{4}{*}{$45(30.0)$} & Ciprofloxacin & QJ01MA02 & $14(9.3)$ \\
\hline & & Enrofloxacin & QJ01MA90 & $12(8.0)$ \\
\hline & & Fluoroquinolone & QJ01MA & $3(2.0)$ \\
\hline & & Levofloxacin & QJ01MA12 & $13(8.7)$ \\
\hline Lincosamide & $1(0.7)$ & Lincomycin & QJ01FF02 & $1(0.7)$ \\
\hline \multirow[t]{3}{*}{ Macrolide } & \multirow[t]{3}{*}{$32(21.3)$} & Azithromycin & QJ01FA10 & $4(2.7)$ \\
\hline & & Erythromycin & QJ01FA01 & $4(2.7)$ \\
\hline & & Tylosin & QJ01FA90 & $24(16.0)$ \\
\hline Oxazolidinone & $3(2.0)$ & Furazolidone (Furasil) & QJ01XE90 & $3(2.0)$ \\
\hline \multirow[t]{2}{*}{ Polypeptide } & \multirow[t]{2}{*}{$52(34.7)$} & Bacitracin Methylene Disalicylate (BMD) & QJ01XX10 & $6(4.0)$ \\
\hline & & Colistin & QJ01XB01 & $46(30.7)$ \\
\hline Pleuromutilin & $5(3.3)$ & Tiamulin & QJ01XQ01 & $5(3.3)$ \\
\hline Sulfonamide & $7(4.7)$ & Sulfonamide & QJ01EQ & $7(4.7)$ \\
\hline \multirow[t]{2}{*}{ Tetracycline } & \multirow[t]{2}{*}{$18(12.0)$} & Chlortetracycline & QJ01AA03 & $8(5.3)$ \\
\hline & & Doxycycline & QJ01AA02 & $10(6.7)$ \\
\hline \multirow[t]{4}{*}{ Combination drug class formulations } & \multirow[t]{4}{*}{$139(92.7)$} & Colidox (Colistin + Doxycycline) & QA07AA98 & $10(6.7)$ \\
\hline & & Dimoxan (Colistin + Amoxicillin) & QA07AA98 & $12(8.0)$ \\
\hline & & Neodox (Neomycin + Doxycycline) & QJ51RG01 & $107(71.3)$ \\
\hline & & Sulphatrim (Sulfamethoxazole + Trimethoprim) & QJ01EW & $10(6.7)$ \\
\hline Don't know & $1(0.7)$ & - & - & $1(0.7)$ \\
\hline Don't use antibiotics & $1(0.7)$ & - & - & $1(0.7)$ \\
\hline
\end{tabular}

India and China [17-19]. The lack of AMR knowledge and judicious use, particularly regarding drugs of high consequence, may further perpetuate its development in food animals and humans in Nepal.

Over $10 \%$ of study participants indicated that they administered antimicrobials for growth promotion, a practice that has been adopted to theoretically increase animal mass for quicker turnout and higher net profits. This corresponds with subtherapeutic dosing, a major AMR contributor, and in Nepal may be responsible for up to $50 \%$ of contaminated retail poultry isolates that express multidrug resistant profiles [20, 21]. This study was not the first to have unearthed the problem of growth promotion use-other reports have illustrated similar injudicious uses of antimicrobials in the livestock sector within LMIC, including Nepal [14, 15, 22].
However, to the authors' knowledge, no previous studies have evaluated AMR knowledge and husbandry practices of Nepalese poultry producers who use antimicrobials for growth promotion. Although only a relatively small percentage of respondents used antimicrobials for growth promotion (13\%), human and animal health organizations have denounced all growth promotion use [23-25]. Nepal's government has acknowledged the need for change, releasing the 2014 National Treatment Guidelines which supported a zero-tolerance policy for growth promotion uses of antimicrobials. In 2017 Nepal took further action to ban importation of antimicrobial enriched feed; however, this policy failed to eliminate incountry antimicrobial enrichment of animal feed. Nepal's Ministry of Livestock Development has also promoted awareness of the issue through training and livelihood 
programs to educate youth interested in animal agriculture [26]. Unfortunately, limited resources have impacted the effectiveness of policy dissemination, enforcement, and monitoring $[14,26]$.

Abiding by withdrawal periods is critical to prevent consumer exposures to antimicrobial residues, and noncompliance with withdrawal periods may indicate lack of knowledge regarding residues, potential contribution to AMR, and general AMR experiences [27]. Only half of the producers surveyed in this study were familiar with withdrawal periods, and among those, only half complied with them. Prior research has demonstrated that the unfamiliarity with antimicrobial residues and withdrawal periods is common among Nepalese producers [15]. Disregard for withdrawal periods may result in antimicrobial residue contamination in the food supply that can expose consumers to unknown levels of antimicrobials. Several studies in Nepal have demonstrated antimicrobial residues in sampled meat ranging from $13 \%$ up to $62 \%$ [28, 29]. Although cooking temperatures destroy antimicrobial residues in meat, inadequately cooked meat may result in antimicrobial residue consumption and two major negative outcomes: antimicrobial resistance development and adverse drug reactions [21]. As mentioned previously, many producers administered colistin, and subtherapeutic ingestion of its residues may lead to resistance development and subsequent infections among individuals with direct poultry contact or through consumption of contaminated meat. In addition to colistin, other drug residues have been found in Nepal's food supply, which is a cause for concern and a priority that Nepal's federal agencies must address $[15,29]$. Currently, the Ministry of Livestock Development and the Department of Livestock services share responsibility to respond to the withdrawal period awareness and observance deficiencies through the National Antimicrobial Surveillance Center [12].

Although Nepal has initiated steps to address AMR challenges through a policy infrastructure and educational awareness, these efforts do not appear to be adequately disseminated nor enforced to promote overall systemic change. Although policy and education campaigns are crucial, they alone may not solve all production practice issues $[15,30,31]$. Policies should consider banning targeted antimicrobials critical to human health, e.g., colistin, coupled with robust monitoring systems that measure antimicrobial uses, including grams of active ingredients and indications. These mechanisms have already been effective in reducing resistance in both humans and animals in countries like China [18, 32]. Nepal may also fill critical policy gaps such as those surrounding feed enrichment and the use of antimicrobials of high consequence for AMR and adverse reactions in humans. Policy accountability can be strengthened through targeted surveillance, consisting of a multifaceted approach to detect AMR infections, product contamination trends, antimicrobial use, and antimicrobial levels in feed. Improved outreach capacities, paired with increased veterinary resources and extensive monitoring in operations and in retail meat products, can create a framework for a regulatory enforcement structure.

\section{Strengths and limitations}

This study provides unique access to commercial poultry operations in the highest product density district in Nepal to assess AMR and antimicrobial use knowledge and practices. This is the first study in Nepal to collect antimicrobial use data in commercial poultry through farmer reporting and farm visit confirmation of products used. This research fills a critical literature gap by assessing AMR knowledge in this frontline agricultural population. Study limitations include the self-reported data dependence and the cross-sectional study design. Unfortunately, self-reported antimicrobials could not all be confirmed through identification of packaging. Additionally, antimicrobial use may be a dynamic or seasonal practice on these farms, which were unable to be evaluated given the study design. Unfortunately, the frequency and dosage of the self-reported antimicrobials could not be ascertained, which is important since reported antimicrobials of high consequence may ultimately be used at a low frequency. Further research is needed to draw causal inferences between antimicrobial use on commercial poultry farms and local AMR epidemiology. It is important to fill AMR surveillance gaps in both food animal and human populations in Nepal and to work with the growing poultry production industry on antimicrobial use education and practice regulations. Due to landslide concerns in the Madi Municipality during the study duration, data from all commercial farms in Madi were retrieved over the phone. Another limitation was the inability to conduct interviews in remote locations; however, these phone interviews did not significantly bias the validity of the data collected from this specific district as all information could easily be ascertained remotely.

\section{Conclusions}

AMR knowledge among Nepal's poultry producers have resulted in poor antimicrobial use practices, including low antimicrobial withdrawal period compliance, significant use of antimicrobials for growth promotion, and the sustained use of critically important antimicrobials. Outreach efforts in combination with increased veterinary resource allocations can educate and provide support for producers as to the benefits of antimicrobial stewardship. Expansive surveillance efforts to monitor 
antimicrobial use and residues in retail meat products may also create a framework for a regulatory enforcement structure to maintain accountability. Upfront investment in these activities is recommended to mitigate AMR and to promote the health of humans, animals, and the environment.

\section{Abbreviations}

AMR: antimicrobial resistance; LMIC: lower- and middle-income country; MoLD: Ministry of Livestock Development; NAP-AMR: National Action Plan for Antimicrobial Resistance; VSDAO: Veterinary Standards and Drug Administration Office

\section{Acknowledgements}

We would like to specially thank the One Health Research Team for their field data collection efforts: Uttam Acharya, Khim B. Ale, Shiva P. Bhusal, Bhanu B. Gautam, Bishnu H. Sharma, Mukesh Nayak, Nabin Neupane, Sujata Regmi, Saroj Sankhi, Manoj L. Sharma, and Sunita Shrestha. We would like to thank participating farmers for their time and support. We would also like to thank the EcoHealth Alliance for their funding support and for connecting our institutions.

\section{Availability of the data and materials}

The datasets generated and analyzed during the current study are not publicly available due to requirements of the Institutional Review Board (IRB) of the Agriculture and Forestry University, in Rampur, Chitwan District, Nepal but are available from the corresponding author on reasonable request.

\section{Authors' contributions}

$A S L, H L, R K B$, and $H B B$ designed the study and $A S L, H L, R K B, H B B$, and $C D H$ created the study survey tool. HBB was the in-country research team lead. $A S L, H L, R K B, H B B$, and the One Health Research Team collected the study data. ASL, GKI, LO, and CDH analyzed the data and drafted the manuscript. All authors edited, read, and approved the final manuscript.

\section{Funding}

This project was funded by the EcoHealth Alliance through the EcoHealthNet Research Exchange program, which is funded by the National Science Foundation (NSF). The funders had no role in study design, data collection and analysis, decision to publish, or preparation of the manuscript.

\section{Ethics approval and consent to participate}

Ethical approval for the study was received by the Agriculture and Forestry University, in Rampur, Chitwan District, Nepal, Institutional Review Board (IRB). Informed consent was obtained by each study participant before enrollment and participation in the study. Written consent was obtained from literate participants. If a potential participant was illiterate, their thumbprint and the signature of a third-party observer was obtained.

\section{Consent for publication}

Not Applicable.

\section{Competing interests}

The authors declare that they have no competing interests.

\section{Author details}

'Department of International Health, Johns Hopkins Bloomberg School of Public Health, Baltimore, MD, USA. ${ }^{2}$ Department of Epidemiology, Rutgers School of Public Health, Piscataway, NJ, USA. ${ }^{3}$ Department of Environmental Health \& Engineering, Johns Hopkins Bloomberg School of Public Health, Baltimore, MD, USA. ${ }^{4}$ Center for Biotechnology, Agriculture and Forestry University, Rampur, Chitwan, Nepal. ${ }^{5}$ Department of Veterinary Microbiology and Parasitology, Agriculture and Forestry University, Rampur, Chitwan, Nepal. ${ }^{6}$ Department of Epidemiology, Johns Hopkins Bloomberg School of Public Health, Baltimore, MD, USA.
Received: 30 June 2020 Accepted: 21 January 2021

Published online: 06 February 2021

\section{References}

1. Tackling Drug-Resistant Infections Globally: Final report and recommendations. The Review on Antimicrobial Resistance; 2016. https:// amr-review.org/sites/default/files/160518_Final\%20paper_with\%20cover.pdf.

2. Centers for Disease Control and Prevention (CDC). Antibiotic Resistance Threats in the United States; 2019. https://www.cdc.gov/drugresistance/pdf/ threats-report/2019-ar-threats-report-508.pdf. Accessed 20 June 2020.

3. OECD.Stemming the Superbug Tide; 2018. https://www.oecd.org/health/ health-systems/Stemming-the-Superbug-Tide-Policy-Brief-2018.pdf. Accessed 18 June 2020.

4. Klein EY, Van Boeckel TP, Martinez EM, et al. Global increase and geographic convergence in antibiotic consumption between 2000 and 2015. Proc Natl Acad Sci 2018;115(15):E3463-E3E70. https://doi.org/10.1073/pnas. 1717295115.

5. Tang KL, Caffrey NP, Nóbrega DB, et al. Restricting the use of antibiotics in food-producing animals and its associations with antibiotic resistance in food-producing animals and human beings: a systematic review and metaanalysis. Lancet Planet Health 2017;1(8):e316-ee27. https://doi.org/10.1016/ s2542-5196(17)30141-9.

6. Van Boeckel TP, Glennon EE, Chen D, et al. Reducing antimicrobial use in food animals. Science 2017;357(6358):1350-1352. https://doi.org/10.1126/ science.aao1495.

7. Aarestrup F. Sustainable farming: get pigs off antibiotics. Nature 2012; 486(7404):465-466. https://doi.org/10.1038/486465a.

8. Popkin BM, Adair LS, Ng SW. Global nutrition transition and the pandemic of obesity in developing countries. Nutr Rev 2012;70(1):3-21. https://doi.org/ 10.1111/j.1753-4887.2011.00456.x.

9. Subedi $M$, Luitel $H$, Devkota $B$, et al. Antibiotic resistance pattern and virulence genes content in avian pathogenic Escherichia coli (APEC) from broiler chickens in Chitwan, Nepal BMC Veterinary Research 2018;14(1):113. https://doi.org/10.1186/s12917-018-1442-z.

10. Food and Agriculture Organization (FAO) of the United Nations. Livestock Country Reviews - Poultry Sector: Nepal. 2014; http://www.fao.org/ publications/card/en/c/eae8604c-c1d7-488a-9b88-b23e5336e653/. Accessed 18 June 2020

11. GARP-Nepal National Working Group (NWG). Executive Summary: Nepal Situation Analysis and Recommendations, 2015; Accessed 18 June 2020

12. Department of Health Services $\mathrm{MoH}$. National Antimicrobial Resistance Containment Action Plan Nepal, 2016; https://www.flemingfund.org/wpcontent/uploads/3d9bf4b7ab190c600921a99cf1803059.pdf. Accessed 20 June 2020.

13. Sergeant ESG. Epitools Epidemiological Calculators. Ausvet. 2018; http:// epitools.ausvet.com.au.

14. Acharya KP, Subramanya SH, Lopes BS. Combatting antimicrobial resistance in Nepal: the need for precision surveillance programmes and multi-sectoral partnership. JAC-Antimicrobial Resistance 2019;1(3). https://doi.org/10.1093/ jacamr/dlz066.

15. Acharya KP, Wilson RT. Antimicrobial Resistance in Nepal. Front Med (Lausanne) 2019;6:105-105. https://doi.org/10.3389/fmed.2019.00105.

16. Pham-Duc P, Cook MA, Cong-Hong H, et al. Knowledge, attitudes and practices of livestock and aquaculture producers regarding antimicrobial use and resistance in Vietnam. PLoS One 2019;14(9):e0223115. https://doi. org/10.1371/journal.pone.0223115.

17. Elbediwi M, Li Y, Paudyal N, et al. Global burden of Colistin-resistant Bacteria: mobilized Colistin resistance genes study (1980-2018). Microorganisms 2019:7(10):461. https://doi.org/10.3390/ microorganisms 7100461

18. Wang $Y, X u C$, Zhang $R$, et al. Changes in colistin resistance and mcrabundance in Escherichia coli of animal and human origins following the ban of colistin-positive additives in China: an epidemiological comparative study. Lancet Infect Dis 2020. https://doi.org/10.1016/S1473-3099(20)301493.

19. Mahalmani VM, Sarma P, Prakash A, et al. Positive list of antibiotics and food products: current perspective in India and across the globe. Indian J Pharmacol 2019:51(4):231-235. https://doi.org/10.4103/ijp.IJP 548 19.

20. Saud B, Paudel G, Khichaju S, et al. Multidrug-resistant Bacteria from raw meat of Buffalo and chicken, Nepal Veterinary Medicine International 2019; 2019:7960268. https://doi.org/10.1155/2019/7960268. 
21. National Research Council. The Effects on Human Health of Subtherapeutic Use of Antimicrobials in Animal Feeds. Washington, DC: The National Academies Press 1980; https://doi.org/10.17226/21.

22. Van Boeckel TP, Pires J, Silvester $R$, et al. Global trends in antimicrobial resistance in animals in low- and middle-income countries. Science 2019; 365(6459). https://doi.org/10.1126/science.aaw1944.

23. World Health Organization (WHO). Global Action Plan on Antimicrobial Resistance. Geneva, Switzerland, 2015; https://apps.who.int/iris/bitstream/ handle/10665/193736/9789241509763_eng.pdf? sequence=1. Accessed 10 June 2020.

24. European Commission. A European one health action plan against antimicrobial resistance (AMR). 2017; https://ec.europa.eu/health/sites/ health/files/antimicrobial_resistance/docs/amr_2017_action-plan.pdf.

25. Center for Veterinary Medicine US Food and Drug Administration (FDA). Guidance for Industry: The Judicious Use of Medically Important Antimicrobial Drugs in Food-Producing Animals. Guid Doc 209, CVM, US FDA Rockville, MD, 2012; https://www.fda.gov/regulatory-information/ search-fda-guidance-documents/cvm-gfi-209-judicious-use-medicallyimportant-antimicrobial-drugs-food-producing-animals. Accessed 20 June 2020.

26. Ministry of Health and Population. Resource mobilisation for antimicrobial resistance (AMR): Getting AMR into plans and budgets of government and development partners Nepal country level report. Draft:: 1-34, 2018; https:// www.who.int/docs/default-source/searo/amr/nepal-amr-integration-reportsept-2018.pdf?sfyrsn=b45d36ac_2. Accessed 10 June 2020.

27. Beyene T. Veterinary drug residues in food-animal products: its risk factors and potential effects on public health. Journal of Veterinary Science and Technology 2015;7:1-7. https://doi.org/10.4172/2157-7579.1000285.

28. Sapkota R, Raut R, Khanal $S$, et al. Screening of antibiotic residue in poultry in Kathmandu valley of Nepal: a cross-sectional study. Archives of Pharmacy and Pharmaceutical Sciences 2019;3(1):079-081. https://doi.org/10.29328/ journal.apps. 1001017.

29. Prajapati M, Ranjit E, Shrestha R, et al. Status of antibiotic residues in poultry meat of Nepal. Nepalese Veterinary Journal 2018;35:55-62. https://doi.org/ 10.3126/nvj.v35i0.25240

30. Haenssgen MJ, Charoenboon N, Zanello G, et al. Antibiotic knowledge, attitudes and practices: new insights from cross-sectional rural health behaviour surveys in low-income and middle-income South-East Asia. BMJ Open 2019;9(8):e028224. https://doi.org/10.1136/bmjopen-2018-028224.

31. Chandler C, Hutchinson E, Hutchison C. Addressing antimicrobial resistance through social theory: an anthropological oriented report. London School of Hygiene and Tropical Medicine. 2016; https://researchonline.Ishtm.ac.uk/ id/eprint/3400500/1/Addressing\%20Antimicrobial\%20Resistance\%2 OThrough\%20Social\%20Theory\%20GOLD\%20VoR.pdf.

32. Perez F, Villegas MV. The role of surveillance systems in confronting the global crisis of antibiotic-resistant bacteria. Curr Opin Infect Dis 2015;28(4): 375-383. https://doi.org/10.1097/QCO.0000000000000182.

Ready to submit your research? Choose BMC and benefit from:

- fast, convenient online submission

- thorough peer review by experienced researchers in your field

- rapid publication on acceptance

- support for research data, including large and complex data types

- gold Open Access which fosters wider collaboration and increased citations

- maximum visibility for your research: over $100 \mathrm{M}$ website views per year

At $\mathrm{BMC}$, research is always in progress.

Learn more biomedcentral.com/submissions 